\title{
Journal of Epidemiology and Public Health Reviews
}

\section{Job Satisfaction Level among the Public Hospital Doctors in Chongqing China and Its associated Factors}

\author{
Li Xi-Tong, Tao Yi and Zhong Xiao-Ni ${ }^{*}$ \\ School of Health and Medicine Management, ChongQing Medical University, China
}

Corresponding author: Zhong Xiao-ni, School of Health and Medicine Management, No.1 Yixueyuan Road, Yuzhong District, Chongqing 400016, P. R. China, Tel: 13308368059; E-mail: zxn66@vip.sina.com, 1145290973@qq.com
Received date: 26 Jan 2016; Accepted date: 29 Feb 2016; Published date: 07 Mar 2016

Citation: Xi-Tong L, Yi T, Xiao-Ni Z (2016) Job Satisfaction Level among the Public Hospital Doctors in Chongqing China and Its associated Factors. J Epidemiol Public Health Rev 2(3): doi http://dx.doi. org/10.16966/2471-8211.111

Copyright: (c) 2016 Xi-Tong L, et al. This is an open-access article distributed under the terms of the Creative Commons Attribution License, which permits unrestricted use, distribution, and reproduction in any medium, provided the original author and source are credited.

\begin{abstract}
Objective: To investigate the job satisfaction level among doctors serving in the public hospitals in Chongqing and its associated factors.

Methods: 589 doctors serving in public hospital in Chongqing were selected as participants through multi-stage stratified random sampling. Each participant received a self-administered questionnaire. Categorical variables were displayed by frequencies, while continuous data by means and standard deviations. Univariate analysis was applied to evaluate the differences between factors of the overall job satisfaction .Two multiple logistic regression analysis using the stepwise method was used to evaluate the influential factors of the overall job satisfaction.

Results: The score of the overall job satisfaction among doctors serving in public hospitals in Chongqing was $3.31 \pm 0.97$, and the associated factors of the overall job satisfaction were learning and training opportunities $(\mathrm{OR}=9.21,95 \% \mathrm{Cl}=2.03-41.85, \mathrm{p}=0.004)$, interpersonal relationship $(\mathrm{OR}=6.29,95 \% \mathrm{Cl}=2.71-14.59, \mathrm{p}=0.000)$, physical working condition $(\mathrm{OR}=6.39,95 \% \mathrm{Cl}=3.87-10.55, \mathrm{p}=0.000)$, promotion opportunity $(\mathrm{OR}=3.44$, $95 \% \mathrm{Cl}=2.12-5.61, \mathrm{p}=0.000)$, reward $(\mathrm{OR}=4.75,95 \% \mathrm{Cl}=2.26-10.01, \mathrm{p}=0.000)$ and service years $(\mathrm{OR}=1.04,95 \% \mathrm{Cl}=1.02-1.07, \mathrm{p}=0.000)$.

Conclusions: The government officials and hospital administrators should pay attention to the factors of influence of job satisfaction and the reasonable demands of the public hospital doctors. In order to improve the overall job satisfaction of doctors in the public hospital in Chongqing, efforts should be made to reform compensation incentive system, expand opportunities of promotion, learning and training, and improve the working conditions and interpersonal relationship.
\end{abstract}

Keywords: Public Hospital Doctor; Job Satisfaction; Compensation Packages

\section{Background}

Recently the healthcare system of China is faced with new challenges, such as the increased healthcare demands and expenditure, inefficient use of healthcare resources, unsatisfying implementation of disease management guidelines, and inadequate healthcare insurance [1], etc. Therefore, in 2009 the Chinese central government launched a landmark program to reform the healthcare system, which aimed at improving health care for all citizens by strengthening disease control and the primary care system. In China, public hospitals are the principal medical and health service institutions, and are essential for public welfare. Therefore, public hospital reform is an important factor for the realization of healthcare system reform in China. Former premier Wen Jiabao considered public hospital reform as one of the most important and challenging tasks in the new healthcare reform $[2,3]$. Doctors in public hospital are responsible for the implementation of the reform policies and the generation of support for the reform. Doctors are also the direct provider of hospital services and key element in the development of health services. The job satisfaction work performance and commitment of doctors directly influence medical safety, service quality, patient satisfaction, doctor-patient relationship, and particularly the operating efficiency and effectiveness of a hospital and hospital management [4]. Several studies show that the job satisfaction of the doctor has a significant effect on the stability of the overall workforce and the quality of the health care delivered [5]. Recent studies note that the job satisfaction and organizational commitment of employees are closely inter-related and correlated with turnover intention [6]. It's significant to improve the job satisfaction of public hospital doctors, in that it can help attract more talented people into health services, ensure the quality of the health care, and promote the reform policies. Therefore, this study analyzes the factors that influence the job satisfaction of doctors in public hospitals in Chongqing. This research aims to suggest concrete areas for improvement to the policy makers, and provide targeted advice to improve doctors' job satisfaction.

\section{Methods \\ Sampling}

The investigation was conducted by Chongqing Medical University during the period of May and August in 2013, managed by National Health and Family planning commission of the People's Republic of China. Chongqing is a southwestern city in China. The reason why Chongqing was selected to conduct this research was that the area has an average number of doctors per thousand people, and the development of economy and medical care of Chongqing is at a medium level in China. Chongqing is composed of 38 counties. This study employed multistage stratified cluster sampling. 9 counties, which included a total of 72 public hospitals ( 9 top class hospitals, 11 second class Hospitals, 52 community health services centers and rural township hospitals), were chosen at the first stage according to the levels of economic development. The questionnaires had been self-administered, and were collected on the spot after completely answered. A total of 589 questionnaires were received, which meant a response rate of $91.00 \%$. 


\section{Measuring instruments}

The self-administered job satisfaction questionnaire for doctors was developed according to Minnesota Satisfaction Questionnaire, MSQ and Job Descriptive Index, JDI, made by National Health and Family planning commission of the People's Republic of China. The questionnaire consisted of two parts. Part 1 included the Socio-demographic characteristics of gender, age, marital status, educational qualification, professional title, hospital class, service years, management position, current employment, average annual income (measured by thousand Yuan), working hours per week, and night watch per month. Part 2 was job satisfaction questionnaire in a five-point Likert form, which included 4 dimensions and 27 items. Of the 4 dimensions, the first one was nature of job (with 3 items about the meaning of the job, 8 items about workload, and 4 items about learning and training opportunities), the second one was working environment (with 2 items about interpersonal relationship and 2 items about physical working condition), the third one was compensation packages (with litem about promotion opportunity and litem about reward), and the fourth one was social environment (with 4 items about doctor-patient relationship, and 1 item about social opinions) and the overall job satisfaction (Table 1). Job satisfaction level questionnaires about a given factor were measured by a 5-point Likert scale: 1 point for absolutely dissatisfied, 2 points for dissatisfied, 3 points for partly satisfied, 4 points for satisfied, and 5 points for absolutely satisfied. A higher overall mean score indicates higher job satisfaction level.

\section{Data analysis}

Statistical analysis was undertaken using the MS Office Excel and SPSS version 22.0 software packages. Categorical variables were reported using percentages, while continuous data were reported using means and standard deviations, univariate analysis was applied to evaluate the differences between factors of the overall job satisfaction. Dependent variable was the overall job satisfaction (the score $\leq 3$ was regarded as 0 -dissatisfied, and the score $>3$ was regarded as 1 -satisfied). Independent variables were gender (female $=0$, male $=1$ ), current employment (temporary $=0$, permanent $=1$ ), management position (yes $=1$, no=0), marital status (single as reference group), education (high school or under as reference group), professional title (primary title as reference group), hospital level (community health services center and rural township hospital as reference group). Age, service years, average annual income per capita (in thousand Yuan), working hours per week, and night watch per month here were analyzed as continuous variables. Meaning of work, workload, learning and training opportunities, interpersonal relationship, physical working condition, promotion opportunity, reward, doctorpatient relationship, social opinions and overall job satisfaction were measured by a 5-point Likert scale: 1 point for absolutely dissatisfied, 2 points for dissatisfied, 3 points for partly satisfied, 4 points for satisfied, and 5 points for absolutely satisfied, the score $\leq 3$ was regarded as 0 -dissatisfied, and the score $>3$ was regarded as 1 -satisfied. The combined impact of the aforementioned risk factors on the overall job satisfaction was considered by means of two multiple logistic regression analysis using the stepwise method, and the odds ratio (OR) was reported with 95\% (CI) where applicable. $5 \%$ was chosen to be level of statistical significance.

\section{Results}

\section{The Socio-demographic characteristics of study sampling}

Table 2 shows the Socio-demographic characteristics of respondents. Among the 589 participants, the majority were male (61.0\%), married $(83.0 \%)$, college-educated or beyond $(70.6 \%)$, permanently employed $(85.7 \%)$. More than half of the respondents $(51.4 \%)$ were of primary title, $28.9 \%$ were of middle title, and $19.7 \%$ were of senior title. Only $29.9 \%$ respondents were in management position. Less than half of the respondents
(40.1\%) worked in top-class hospitals, $34.1 \%$ worked in second-class hospitals, and only $25.8 \%$ worked in community health services centers and rural township hospitals. The average age of respondents was 37.31 years (ranging from 22 to 59) with an average working experience of 14.34 years (ranging from 1 to 43 ). $83.02 \%$ respondents worked for more than 40 hours per week, and average working hours was 58.15 hours. The average night watches per month were 4.95 . The average annual income was 45.89 thousand RMB ( $\$ 1.00=6.23 \mathrm{RMB}$ in 2013$)$.

\section{Level of job satisfaction among doctors}

The overall job satisfaction mean score was 3.31, ranging from 1.00 to 5.00 and standard deviation was 0.97 . Nature of satisfaction with the work itself mean score was 3.00 ranging from 1.53 to 4.27 , standard deviations was 0.32 (The mean scores of meaning of work, workload, and learning and training opportunities were respectively $4.30 \pm 0.72$, $1.90 \pm 0.57$ and $4.21 \pm 0.65$ ). Work environment satisfaction mean score was 3.44 ranging from 1.50 to 5.00 , standard deviations was 0.75 (The mean scores of interpersonal relationship and physical working condition were respectively $3.86 \pm 0.77$ and $3.03 \pm 0.98$ ). Compensation packages satisfaction mean score was 2.93 ranging from 1.00 to 5.00 , standard deviations was 0.95 (The mean score of promotion opportunity and reward were respectively $3.25 \pm 1.01$ and $2.61 \pm 1.14$ ). Social environment mean score was 3.28 ranging from 1.00 to 5.00 , standard deviations was 0.65 (The mean scores of doctor-patient relationship and social opinions were respectively $3.36 \pm 0.64$ and $2.95 \pm 1.023$ ) (Table 1 ).

\section{Univariate analysis of the factors that influence the overall job satisfaction degree of doctors}

This study used univariate analysis to determine the correlation between all variables (including socio-demographic factors and the 4 dimensions of job satisfaction level) and the overall job satisfaction level of doctors. The overall job satisfaction level (numbered from 1 to 5) was evaluated on a five-point scale, and reported using means and standard deviations. The results showed that, among the socio-demographic and job satisfaction level variables of doctors, current employment $(\mathrm{F}=6.69$, $\mathrm{P}=0.01)$, working hours per week $(\mathrm{F}=6.53, \mathrm{P}=0.00)$, night watches per month $(\mathrm{F}=4.13, \mathrm{P}=0.02)$, significance of work $(\mathrm{F}=5.99, \mathrm{P}=0.02)$, learning and training opportunities $(\mathrm{F}=38.22, \mathrm{P}=0.00)$, interpersonal relationship $(\mathrm{F}=98.86, \mathrm{P}=0.00)$, physical working condition $(\mathrm{F}=233.43$, $\mathrm{P}=0.00)$, promotion opportunity $(\mathrm{F}=195.20, \mathrm{P}=0.00)$, reward $(\mathrm{F}=153.22$, $\mathrm{P}=0.00)$, doctor-patient relationship $(\mathrm{F}=44.39, \mathrm{P}=0.00)$ and social opinion $(\mathrm{F}=24.87, \mathrm{P}=0.00)$ were related to the overall job satisfaction level of doctors (Table 2).

\section{Analysis of the multiple factors that influence the overall level of job satisfaction of doctors}

The binary logistic regression method was used to analyze the factors that influence the overall job satisfaction level of doctors. We analyzed the significantly related factors $(\mathrm{p}<0.05)$ obtained from a previous study. Learning and training opportunities, interpersonal relationship, physical working condition, promotion opportunity, reward, service years were significantly related to the overall job satisfaction level of doctors.

The overall job satisfaction level of doctors who were satisfied with their learning and training opportunities was 9.212 times higher than that of the doctors who were dissatisfied with their self-development $(\mathrm{OR}=9.21,95 \% \mathrm{CI}=2.03-41.85, \mathrm{p}=0.004)$. The overall job satisfaction level of doctors who were satisfied with their interpersonal relationship was 6.292 times higher than that of the doctors who were dissatisfied with their interpersonal relationship $(\mathrm{OR}=6.29,95 \% \mathrm{CI}=2.71-14.59$, $\mathrm{p}=0.000$ ). The overall job satisfaction level of doctors who were satisfied with their physical working condition was 6.389 times higher than that of the doctors who were dissatisfied with their physical working condition 
Overall job satisfaction

Nature of satisfaction with the work itself

My work is quite influential to people's life

My work performance is influential to many people

My work is very meaningful and very important

\section{Workload}

My work requires great attention

My work puts many demands on my ability

My work needs me to invest much time and energy

I have many tasks to accomplish

My unit arranges much work on me

I often can't accomplish the tasks assigned me

Generally, I feel great pressure from the work

Generally, I feel my work highly intense

\section{Learning and training opportunities}

The work means a learning and developing process to me

My expertise and skill gradually grow through the work

I can try the new things and develop my potentials through work

The work doesn't help my personal growth in any sense

Working environment satisfaction

\section{Interpersonal relationship}

I am very satisfactory with my colleagues

I am very satisfactory with my immediate leader

\section{Physical working condition}

I am very satisfactory with the hospital's physical environment

I am very satisfactory with the hospital's facilities

Compensation packages satisfaction

Promotion opportunity

I am very satisfactory with promotion opportunities

Reward

I am very satisfactory with the reward from the hospital

\section{Social Environment satisfaction}

Doctor-patient relationship

How much do you feel respected by the patients

How much do you feel your service trusted by the patients

How much are your patients satisfactory with your service

How do you think is the current doctor-patient relationship

\section{Social opinions}

How much do you think your profession is respected by the society

How much do you think your profession is respected by the society

Table 1: Variables of job satisfaction questionnaire and degree of job satisfaction among doctors

$(\mathrm{OR}=6.39,95 \% \mathrm{CI}=3.87-10.55, \mathrm{p}=0.000)$. Compared with the doctors who were dissatisfied with promotion opportunity, doctors who were satisfied with promotion opportunity had the overall job satisfaction level that was 3.444 times higher $(\mathrm{OR}=3.44,95 \% \mathrm{CI}=2.12-5.61, \mathrm{p}=0.000)$. Compared with the doctors who were dissatisfied with their reward, doctors who were satisfied with their reward had the overall job satisfaction level that was 4.752 times higher $(\mathrm{OR}=4.75,95 \% \mathrm{CI}=2.26-10.01, \mathrm{p}=0.000)$. The overall job satisfaction level of doctors who serviced more years was 0.042 times higher than that of the doctors who serviced less years $(\mathrm{OR}=1.04$, 95\% CI=1.02-1.07, p=0.000) (Table 3).

Note: Gender $(\mathrm{p}=0.717)$, age $(\mathrm{p}=0.564)$, current employment $(\mathrm{p}=0.564)$, management position $(\mathrm{p}=0.301)$, marital status (marriage $\mathrm{p}=0.385$, other(s) $\mathrm{p}=0.122$ ), education (college graduate $\mathrm{p}=0.081$, master

Citation: Xi-Tong L, Yi T, Xiao-Ni Z (2016) Job Satisfaction Level among the Public Hospital Doctors in Chongqing China and Its associated Factors. J Epidemiol Public Health Rev 2(3): doi http://dx.doi.org/10.16966/2471-8211.111 
Open Access

\begin{tabular}{|c|c|c|c|c|c|}
\hline Characteristics & No. & $(\%)$ & Mean \pm SD & T/F & $\mathbf{P}$ \\
\hline Nature of satisfaction with the work itself Hospital level & & & & 0.36 & 0.7 \\
\hline Community health services center and rural township hospital & 236 & 40.07 & $3.34 \pm 0.98$ & & \\
\hline Second class Hospital & 201 & 34.13 & $3.26 \pm 0.90$ & & \\
\hline Top class hospital & 152 & 25.81 & $3.31 \pm 1.04$ & & \\
\hline Gender & & & & 0.45 & 0.5 \\
\hline Female & 230 & 39.05 & $3.27 \pm 0.95$ & & \\
\hline$<40$ & 369 & 62.65 & $3.29 \pm 0.96$ & & \\
\hline $40-59$ & 220 & 37.35 & $3.34 \pm 0.99$ & & \\
\hline Marital status & & & & 1.44 & 0.24 \\
\hline Single & 90 & 15.28 & $3.29 \pm 0.96$ & & \\
\hline Marriage & 489 & 83.02 & $3.32 \pm 0.97$ & & \\
\hline Other (s) & 10 & 1.7 & $2.8 \pm 1.14$ & & \\
\hline Master or above & 104 & 17.66 & $3.34 \pm 1.07$ & & \\
\hline Professional title & & & & 2 & 0.14 \\
\hline Junior title & 303 & 51.44 & $3.35 \pm 0.98$ & & \\
\hline Intermediate title & 170 & 28.86 & $3.18 \pm 0.89$ & & \\
\hline Senior title & 116 & 19.69 & $3.37 \pm 1.03$ & & \\
\hline Service years & & & & 2.17 & 0.09 \\
\hline$<5$ & 139 & 23.6 & $3.43 \pm 0.96$ & & \\
\hline 14-May & 192 & 32.6 & $3.19 \pm 0.97$ & & \\
\hline $15-24$ & 142 & 24.11 & $3.26 \pm 0.90$ & & \\
\hline$\geq 25$ & 116 & 19.69 & $3.41 \pm 1.05$ & & \\
\hline$<40 \mathrm{~h}$ & 100 & 16.98 & $3.6 \pm 1.03$ & & \\
\hline $41-80 \mathrm{~h}$ & 425 & 72.16 & $3.27 \pm 0.96$ & & \\
\hline$\geq 81 \mathrm{~h}$ & 64 & 10.87 & $3.09 \pm 0.83$ & & \\
\hline \multicolumn{6}{|l|}{ night watches per month } \\
\hline 0 & 142 & 24.11 & $3.48 \pm 0.99$ & 4.13 & $0.02^{*}$ \\
\hline $0-4$ & 162 & 27.5 & $3.35 \pm 1.03$ & & \\
\hline$\geq 5$ & 285 & 48.39 & $3.2 \pm 0.91$ & & \\
\hline Average annual income(in thousand Yuan) & & & & 1.88 & 0.11 \\
\hline The lower level & 118 & 20.03 & $3.46 \pm 1.00$ & & \\
\hline Between middle and lower & 116 & 19.69 & $3.16 \pm 1.02$ & & \\
\hline Middle level & 123 & 20.88 & $3.37 \pm 0.86$ & & \\
\hline Between upper and middle & 104 & 17.66 & $3.20 \pm 0.98$ & & \\
\hline The upper level & 128 & 21.73 & $3.34 \pm 0.97$ & & \\
\hline \multicolumn{6}{|l|}{ Nature of satisfaction with the work itself } \\
\hline Meaning of work & & & & 5.99 & $0.02^{*}$ \\
\hline Dissatisfied & 41 & 6.96 & $2.95 \pm 1.18$ & & \\
\hline Satisfied & 548 & 93.04 & $3.33 \pm 0.95$ & & \\
\hline
\end{tabular}

Citation: Xi-Tong L, Yi T, Xiao-Ni Z (2016) Job Satisfaction Level among the Public Hospital Doctors in Chongqing China and Its associated Factors. J Epidemiol Public Health Rev 2(3): doi http://dx.doi.org/10.16966/2471-8211.111 
Open Access

\begin{tabular}{|c|c|c|c|c|c|}
\hline Workload & & & & 0.2 & 0.65 \\
\hline Dissatisfied & 572 & 97.11 & $3.30 \pm 0.95$ & & \\
\hline Satisfied & 17 & 2.89 & $3.41 \pm 1.46$ & & \\
\hline Dissatisfied & 38 & 6.45 & $2.39 \pm 0.95$ & & \\
\hline Satisfied & 551 & 93.55 & $3.37 \pm 0.94$ & & \\
\hline \multicolumn{6}{|l|}{ Working environment satisfaction } \\
\hline Dissatisfied & 129 & 21.9 & $2.61 \pm 0.86$ & & \\
\hline Satisfied & 460 & 78.1 & $3.50 \pm 0.91$ & & \\
\hline Physical working condition & & & & 233.43 & $0.00^{*}$ \\
\hline Dissatisfied & 382 & 64.86 & $2.93 \pm 0.84$ & & \\
\hline Dissatisfied & 368 & 62.48 & $2.93 \pm 0.88$ & & \\
\hline Satisfied & 221 & 37.52 & $3.93 \pm 0.78$ & & \\
\hline Reward & & & & 153.22 & $0.00^{*}$ \\
\hline Dissatisfied & 476 & 80.81 & $3.09 \pm 0.91$ & & \\
\hline Satisfied & 113 & 19.19 & $4.21 \pm 0.66$ & & \\
\hline \multicolumn{6}{|l|}{ Social Environment } \\
\hline Doctor-patient relationship & & & & 44.39 & $0.00^{*}$ \\
\hline Dissatisfied & 187 & 31.75 & $2.93 \pm 0.97$ & & \\
\hline Satisfied & 402 & 68.25 & $3.48 \pm 0.92$ & & \\
\hline Social opinion & & & & 24.87 & $0.00^{*}$ \\
\hline
\end{tabular}

Table 2: Job satisfaction facets mono factor analysis of variance $(\mathrm{N}=589)$

* means $p<0.05$, and the difference is of statistical significance.

\begin{tabular}{|c|c|c|c|c|c|c|}
\hline \multirow{2}{*}{ Factors } & \multirow{2}{*}{ B } & \multirow{2}{*}{ Wald } & \multirow{2}{*}{$\mathbf{P}$} & \multirow{2}{*}{ OR } & \multicolumn{2}{|c|}{$95 \% \mathrm{Cl}$} \\
\hline & & & & & Lower & Upper \\
\hline Learning and training opportunities & 2.22 & 8.268 & 0.004 & 9.21 & 2.03 & 41.85 \\
\hline Interpersonal relationship & 1.839 & 18.38 & 0 & 6.29 & 2.71 & 14.59 \\
\hline Physical working condition & 1.855 & 52.571 & 0 & 6.39 & 3.87 & 10.55 \\
\hline Promotion opportunity & 1.237 & 24.695 & 0 & 3.44 & 2.12 & 5.61 \\
\hline Reward & 1.558 & 16.801 & 0 & 4.75 & 2.26 & 10.01 \\
\hline
\end{tabular}

Table 3: Analysis of the multiple factors that influence the overall job satisfaction level

or above $\mathrm{p}=0.487$ ), professional title (intermediate title $\mathrm{p}=0.034$, senior title $\mathrm{p}=0.864$ ), hospital level (second class hospital $\mathrm{p}=0.324$,Top class hospital $\mathrm{p}=0.168$ ), average annual income per capita (in thousand Yuan) $(\mathrm{p}=0.869)$, working hours per week $(\mathrm{p}=0.210)$ and night watch per month here $(\mathrm{p}=0.091)$, meaning of work $(\mathrm{p}=0.810)$, workload $(\mathrm{p}=0.084)$, doctor-patient relationship ( $\mathrm{p}=0.079)$, and social opinions $(\mathrm{p}=0.716)$ were insignificant and were not considered in the model.

\section{Discussion}

This study was one of the most recent efforts to focus on the overall job satisfaction of doctors in Chongqing, China and its influential factors. The 589 respondents were interviewed by the self-administered job satisfaction questionnaire for doctors. The mean value of the overall job satisfaction $(3.31 \pm 0.97)$ was consistent with this in earlier studies on job satisfaction [7-9].

To assess the overall job satisfaction of doctors, we further analyzed the factors influencing the overall job satisfaction of doctors by univariate and multivariate analyses. Univariate analysis results showed that current employment, working hours per week, night watches per month, meaning of work, learning and training opportunities, interpersonal relationship, physical working condition, promotion opportunity, reward, doctorpatient relationship, and social opinions were related to the overall job satisfaction degree of doctors. However, multivariate analysis results showed that only learning and training opportunities, interpersonal relationship, physical working condition, promotion opportunity, and

Citation: Xi-Tong L, Yi T, Xiao-Ni Z (2016) Job Satisfaction Level among the Public Hospital Doctors in Chongqing China and Its associated Factors. J Epidemiol Public Health Rev 2(3): doi http://dx.doi.org/10.16966/2471-8211.111 
reward were significantly associated with the overall job satisfaction degree of doctors. None of the socio-demographic characteristics exhibited a significant correlation. It indicated that the influence on the overall job satisfaction degree of doctors from socio-demographic characteristics in this study was weaker than that from the nature of satisfaction with work itself, working environment, and compensation packages. This phenomenon could be attributed to great changes in the working conditions of medical staff and work-related factors in hospitals in China as a result of the implementation of the healthcare reform and hospital reform. Therefore, socio-demographic characteristics did not strongly influence job satisfaction, whereas the nature of satisfaction with work itself, working environment and compensation packages were statistically significant [4]. The results of multivariate analysis indicated learning and training opportunities, interpersonal relationship, physical working condition, promotion opportunity, and rewards could result in more job satisfaction. These findings are consistent with those in earlier studies on job satisfaction [5,10-23]. For example, Janus K and Kumar R $[24,25]$ conducted a survey in seven sub-Saharan African countries; the result shows that professional development and training opportunities are the most important factor resulting in job satisfaction. Peters and his co-workers [26] found that many employees in India rated "training opportunities" as one of the motivating factors. Dolea C [27] has found that opportunities for personal development, pay/reward, management practices and organizational policies were important determinants of job motivation. The survey of Sara et al. [21] shows that international relationship, pay satisfaction, skill development, workplace civility, and satisfaction with senior management were positive factors. The results showed that income, the way organization policies are put into practice, amount of work, chances for advancement in the job, and working conditions are significant factors that contribute to the turnover intention of village doctors [27]. A study in Vietnam has also found that the main motivating factors of doctors include the following: the appreciation expressed by their managers, competitive income, and training [28]. Doctors in Ghana overwhelmingly identify low salaries as the main source of dissatisfaction on an interviewer-administered questionnaire [29].

The doctors in public hospital in Chongqing were evidently less satisfactory with the reward $(2.61 \pm 1.14)$ than with other factors of influence of the overall job satisfaction. This indicated that doctors considered that current remuneration did not match the amount of work, and the current remuneration provided for them did not satisfy the demands. At present, the average annual income of doctors in Chongqing ( 45.89 thousand RMB) is basically the same as the average annual income in other cities. The income level of public hospital doctors in China is well below the international one [4]. In this study, public hospital doctors in Chongqing were exposed to higher work-related stress. This result could be attributed to the increasing number of patients, higher requirements for proficiency and comprehensive quality of medical staff, and reform measures of hospital administration system against the background of public hospital reform [30]. Because of the healthcare reform, the medical care demand of the population is released and doctors must treat more patients. In China, many jobs require employees to work for only 8 hours a day, but the results of this study showed that more than half of the doctors $(83.03 \%)$ in government owned hospitals in Chongqing work longer than that, and $75.89 \%$ of the respondents work overtime at night.

Therefore, the government officials and hospital administrators should pay attention to these factors of influence and pay more attention to the needs of the doctors in public hospitals in Chongqing. At present four main aspects call for most attention: [31,32]
1. The hospital administrators should show more concern for the working conditions of the doctors in public hospitals, properly assign and arrange work, and appropriately reduce workload and work stress to promote job satisfaction.

2. The government officials and hospital administrators should improve the system of compensation packages, enhance income levels, and make the income match the workload and technical value of doctors in public hospitals.

3. More learning and training opportunities should be provided and created for doctors in public hospitals, in order to help them to improve their professional level and meet their individual development requirements.

4. Better interpersonal relationship and management system should be provided for the doctors in public hospitals, in order to promote their job satisfaction.

\section{Possible Limitations}

In this study, there are three possible limitations: first, a larger sample size and better sampling methods might result in a more conclusive comparison of job satisfaction in the future. Second, given that the study was conducted only in government owned hospitals of Chongqing, the findings of the study may not apply to doctors working in other areas in China.

\section{Conclusion}

The results of the investigation conducted in Chongqing showed that the satisfaction levels of reward $(2.61 \pm 1.14)$, physical working condition $(3.03 \pm 0.98)$, and promotion opportunity $(3.25 \pm 1.01)$ were lower than those of other aspects. More than half (60.95\%) of doctors were dissatisfactory with their present job. The overall job satisfaction mean score was $3.31 \pm 0.97$. Self-development, interpersonal relationship, physical working condition, promotion opportunity, reward, and service years were significantly related to the overall job satisfaction level of doctors. The findings may be of interest to policy makers in health department considering the consequences of the current shortage of doctors. This study has highlighted the factors of influence of job satisfaction of doctors who devote themselves to health care services in Chongqing.

\section{References}

1. Wang C, Rao K, Wu S, Liu Q (2013) Health care in China: improvement, challenges, and reform. Chest 143: 524-531.

2. Ding Y, Smith HJ, Fei Y, Xu B, Nie S, et al. (2013) Factors influencing the provision of public health services by village doctors in Hubei and Jiangxi provinces. China Bull World Health Organization 91: 64-69.

3. Shi L, Hung LM, Song K, Sarika R, Jenna T, et al. (2013) Chinese primary care physicians and work attitudes. Int J Health Serv 43: 167181.

4. Fang P, Luo Z, Fang Z (2015) What is the job satisfaction and active participation of medical staff in public hospital reform: a study in Hubei province of China. Hum Resour Health 13: 34.

5. Zhang $Y$, Feng $X$ (2011) The relationship between job satisfaction, burnout, and turnover intention among physicians from urban stateowned medical institutions in Hubei, China: a cross-sectional study. BMC Health Serv Res 11: 235.

6. Mobley WH (1977) Intermediate linkages in the relationship between job satisfaction and employee turnover. J Appl Psychol 62: 237-240.

7. Mosadeghrad AM, Ferlie E, Rosenberg D (2008) A study of the relationship between job satisfaction, organizational commitment and turnover intention among hospital employees. Health Serv Manage Res 21: 211-227. 
8. Fang P, Liu X, Huang L, Zhang X, Fang Z (2014) Factors that influence the turnover intention of Chinese village doctors based on the investigation results of Xiangyang City in Hubei Province. Int $\mathrm{J}$ Equity Health 13: 84.

9. Puriene A, Petrauskiene J, Janulyte V, Balciuniene I (2007) Factors related to job satisfaction among Lithuanian dentists. Stomatologija 9: 109-113.

10. Li L, Zhang Z, Sun Z, Zhou H, Liu X, et al. (2014) Relationships between actual and desired workplace characteristics and job satisfaction for community health workers in China: a cross-sectional study. BMC Fam Pract 15: 180

11. Visser MR, Smets EM, Oort FJ, De Haes HC (2003) Stress, satisfaction and burnout among Dutch medical specialists. CMAJ 168: 271-275.

12. Hills D, Joyce C, Humphreys $\mathrm{J}$ (2012) Validation of a job satisfaction scale in the Australian clinical medical workforce. Eval Health Prof 35: 47-76.

13. Nylenna M, Gulbrandsen P, Førde R, Aasland OG (2005) Unhappy doctors? A longitudinal study of life and job satisfaction among Norwegian doctors 1994-2002. BMC Health Serv Res 5: 44.

14. Pathman DE, Konrad TR, Williams ES, Scheckler WE, Linzer M, et al. (2002) Physician job satisfaction, dissatisfaction, and turnover. J Fam Pract 51: 593.

15. Murrells T, Robinson S, Griffiths P (2008) Is satisfaction a direct predictor of nursing turnover? Modelling the relationship between satisfaction, expressed intention and behaviour in a longitudinal cohort study. Hum Resour Health 6: 22.

16. Lambrou P, Kontodimopoulos N, Niakas D (2010) Motivation and job satisfaction among medical and nursing staff in a Cyprus public general hospital. Hum Resour Health 8: 26-34.

17. McGlynn K, Griffin MQ, Donahue M, Fitzpatrick JJ (2012) Registered nurse job satisfaction and satisfaction with the professional practice model. J Nurs Manage 20: 260-265.

18. Pillay R (2008) Work satisfaction of medical doctors in the South African private health sector. J Health Organ Manag 22: 254-268.

19. Taylor K, Lambert T, Goldacre M (2008) Career destinations, job satisfaction and views of the UK medical qualifiers of 1977 . J R Soc Med 101: 191-200.

20. Wenderlein FU (2003) Work satisfaction and absenteeism of nursing staff-comparative study of 1021 nurse trainees and nurses. Gesundheitswesen 65: 620-628.
21. Sara DG, Joeri $H$, Roland $P$ (2011) Revisiting the impact of job satisfaction and organizational commitment on nurse turnover intention: an individual differences analysis. Int J Nurs Stud 48: 15621569.

22. Gardulf A, Orton ML, Eriksson LE, Undé M, Arnetz B, et al. (2008) Factors of importance for work satisfaction among nurses in a university hospital in Sweden. Scand J Caring Sci 22: 151-160.

23. Tellez M (2012) Work satisfaction among California registered nurses: a longitudinal comparative analysis. Nurs Econ 30: 73-81.

24. Janus K, Amelung VE, Baker LC, Gaitanides M, Schwartz FW, et al. (2008) Job satisfaction and motivation among physicians in academic medical centers: insights from a cross-national study. J Health Polit Policy Law 33: 1133-1167.

25. Kumar R, Ahmed J, Shaikh BT, Hafeez R, Hafeez A (2013) Job satisfaction among public health professionals working in public sector: a cross sectional study from Pakistan. Hum Resour Health 11: 2 .

26. Peters DH, Subrata C, Prasanta M, Steinhardt L (2010) Job satisfaction and motivation of health work in public and private sectors: crosssectional analysis from two Indian states. Laura Steinhardt Hum Resour Health 8: 27.

27. Dolea C, Adams O (2005) Motivation of health care workers-review of theories and empirical evidence. Cah Sociol Demogr Med 45: 135136.

28. Dieleman M, Cuong PV, Anh LV, Martineau T (2003) Identifying factors for job motivation of rural health workers in North Viet Nam. Hum Resour Health 5: 10.

29. Agyepong I, Anafi P, Asiamah E, Ansah EK, Ashon DA, et al. (2004) Health worker (internal customer) satisfaction and motivation in the public sector in Ghana. Int J Health Plann Manage 19: 319-336.

30. Hou JL, Li N, Lu L, Li JZ, Ma J (2013) Research on job satisfaction degree primary healthcare workers after health care system reform in Shanghai City. Chin Hospital Manage 33: 10-12.

31. Luo Z, Bai X, Min R, Tang C, Fang $P$ (2014) Factors influencing the work passion of Chinese community health service workers: an investigation in five provinces. BMC Fam Pract 15: 77.

32. Sun $Y$, Luo $Z$, Fang $P$ (2013) Factors influencing the turnover intention of Chinese community health service workers based on the investigation results of five provinces. J Community Health 38: 10581066. 